\title{
Microcontroller Based Seed Metering System for Precise Soybean Seeding
}

\author{
Rohit Namdeo $^{1}$, Kunj Bihari Tiwari ${ }^{1}$, Atul Kumar Shrivastava ${ }^{\text {*, }}$ \\ Manish Patel ${ }^{1}$ and Bharati Das ${ }^{2}$ \\ ${ }^{1}$ Department of Farm Machinery and Power Engineering, College of Agricultural \\ Engineering, JNKVV, Jabalpur - 482004, India \\ ${ }^{2}$ Instrument development \& Service Center, JNKVV, Jabalpur-482002, India \\ *Corresponding author
}

\section{A B S T R A C T}

\section{Keywords}

Microcontroller, Precise seeding, Precision agriculture, Seed drill

Article Info

Accepted:

23 April 2020

Available Online:

10 May 2020
For the uniform seeding over the field, the performance of seed metering device is vital. While a seed drill is on work, during the field operation undesired situation such as slipping and skidding of the ground wheel, vibration, seizing, and jamming on the chain-sprocket system may occur especially at high speed. To overcome these problems, it was aimed to develop an electronically controlled Seed metering system (ECSMS) for seed drill. The developed system was incorporated with geared dc motor, proximity sensor, variable speed rate controller, and microcontroller as the prime components. The performance evaluation of an electronically controlled metering system was done at four different levels of speeds $2.4,3,4$ and $5 \mathrm{~km} / \mathrm{h}$ at 20 $\mathrm{cm}$ row to row spacing under the laboratory condition. A comparison was done between the set seed rate and actual seed rate regarding the seed rate variation and uniformity. The average percentage variation between the actual seed rate over the selected input seed rate was found to be within the range of -3.10 to $3.141 \%$ at a different level of seed rate and forward speeds. ECSMS enabled the suggested optimum seeding rate, a quick and simple setting possibility, synchronize and realtime control, the ability to work under higher speeds.

\section{Introduction}

Precision agriculture is the precise application of agricultural resources such as seeds, fertilizer, herbicides, and irrigation water to meet the necessities of required fertility levels of soil. The principal factors which affect the optimal seeding rate in the field are moisture content and fertility of the soil. During the growth of crops equally distribution of nutrition and available moisture in the soil to the plants, affected by the uniformity of seed rate. The maximum yield in cultivated land significantly occurs at the optimal seeding rates (Mcbratney, 2006). Previous studies have shown that the uniform seed rate over the field decreases yield loss, competition between plant, and also the production cost of 
the crop (Kamgar et al., 2015). This can be achieved by precision sowing machinery (Karayel, 2009).

Throughout the field operation of the seed drill, the performance of the metering system is a very important parameter to attain a homogeneous seed rate over the field. In existing seed drill and planter, the motion is transferred from the ground drive wheel to the seed metering shaft employing mechanical drive components such as chain-sprocket, gearbox, and shaft. These machines are commonly used at present and even though they are acknowledged to have sufficient performance, but they still have many shortcomings. While operating these machines at high speed and crop residues present in the field, undesired situations occurred such as spinning and skidding of the ground drive wheel, seizing, and jamming onchain and sprocket systems (Iacomi and Popescu, 2015; Liang et al., 2015). It is reported that planting accuracy of planting machines severely reduces due to the lack of traction between the ground dive wheel and soil. It is studied that low traction between the ground drive wheel and soil greatly influences the performance of planting and sowing machinery. It is practically observed that factors such as crop residues, stubbles in the field, uneven topography, and high resistant torque on the ground drive wheel result in the negative slippage of the ground dive wheel.

The skid or negative slippage between $6.08 \%$ and $8.77 \%$ was reported on the studies conducted on the different precision planter. (Cay et al., 2018). Skidding of the ground wheel alters the seed rate of the seed drill and planter. Also, the stepwise output of seed metering unit transmission of conventional grain drills leads to poor seeding rate control. It is a necessity to improve components of seed drill to eliminate that problem (Aykas et al., 2013).
To overcome that negativities mentioned above, electronic and hydraulic controlled drive developed to drive the metering system with replacement of mechanical systems (Iacomi and Popescu, 2015; Liang et al., 2015; Miller et al., 2012). In recent years, the main changes have arisen in the seed metering mechanism of grain drills in a specific situation. The general and ordinary forms of the seed metering mechanism of the grain drills have been replaced with the pneumatic metering devices. Various studies were done on the constructional parameter of seed metering system such as hole, shape, and size of the plate as well as vacuum pressure, the position of the metering plate (horizontal and vertical) (Singh et al., 2005; St Jack et al., 2013).

Kamgar et al., (2013) developed and increased the efficiency of the precision planter by using mechatronics. They use a processor, dc motor, and electronic circuit to operate the seed metering unit. They found that the mechatronics system had better seeding performance than the mechanical system.

To increase the efficiency of precision planter mechatronics (Liang et al., 2015; Kamgar et al., 2013) and electronic solenoid valves (Iacomi and Popescu, 2015) were used to the developed transmission system of the machine. It is observed that some manufactures developed various designs using geared dc motors, hydraulic motors to precise metering of seed. Yet these machines are complex and required special provision and skill to operate. The cost of these machines is much higher as compared to existing machines. In addition to these, experimental studies to overcome the negativities mentioned in planters and to develop different drive systems to precisely and accurately adjust the metering on different and step-less seed spacing are still in 
progress. It was mainly aimed to develop an electronically controlled seed metering unit to get uniform seed rate over the field system and to investigate the usability for soybean seed. This study was undertaken with an objective to reduce the seed rate variability of seed metering system by replacing mechanical components of an existing seed drill with microcontroller- controlled DC motor and other sensors. This study was done at the laboratory of department of Farm Machinery and Power Engineering, Jawaharlal Nehru Krishi Vishwavidyalaya, India.

\section{Materials and Methods}

\section{Development of electronically controlled seed metering unit for seed drill}

In conventional seed drill, drive to seed metering shaft is taken from ground drive wheel employing chain, sprocket, gear, and belt drives. These ordinary mechanical transmission systems are less efficient and exist with some losses while operating in the field. It also subjected to wear and tear due to mechanical vibration and friction during the field operation. In addition to this Ground, Drive Wheel is skids some time due to a lot of obstacles and crop residues present in the field result in non-uniformity of seed rate over the field. To avoid these problems, it was decided to replace the ordinary seed metering unit of seed drill with developed electronically controlled seed metering unit.

Based on the working principle of mechanical drive systems of the existing seed drill, the conceptual design approach was used to create schematic designs and functional lab setup of the electronically controlled seed metering system for seed drill as shown in Fig. 1 and 2.

Electronically controlled seed metering system was composed of geared dc motor, microcontroller, proximity sensors with encoded wheels, simulated front wheel of tractor, variable speed controller, and other cables and connectors associated with embedded circuits. Geared dc motor of high torque was selected based on torque and power requirements. That DC motor was used to drive metering shaft employing chain and sprockets type power transmission arrangement.

It was required for the motor to be capable enough to vary its speed according to the forward speed of operation and provide enough torque to rotate the seed metering shaft of the seed drill. To achieve that feature the variable speed controller was used to control the speed of geared dc motor. Pulse width modulation (PWM) technique was used as motor speed control methods corresponding to forward speed of operation as a system with feedback were designed (for self-control).

Whereas small dc motor with incorporated 8 spokes iron wheel was used to develop the simulated front wheel of the tractor. To very its speed potentiometric switch was provided. One Proximity sensor with encoder wheels was used to detect the forward speed of operation (from the simulated front wheel of the tractor) and another one was used to detect the rotational speed of the seed metering shaft of the seed drill. Control unit facilitated with a user-friendly input button to select seed rate from $40 \mathrm{~kg}$ per hectare to 100 kg per hectare.

The microcontroller process the required speed of the seed metering shaft by using functional algorithms and signals from the proximity sensors. The system was designed as a platform with a microcontroller that controlled the motor speed, as per the desired output, provided inputs and feedback signals. The C-based programming language was used; the prepared program by using the 
Arduino compiler was transferred and uploaded in the microcontroller. For programming, the different mathematical values were established. The rolling radius of the tractor front wheel was calculated and that was used to convert the signal pulse of the proximity sensor to forward speed of operation. The pulse signal from the proximity sensor of the metering shaft was used in programming and converts it in rpm of the metering shaft as a feedback input to the microcontroller.

\section{Working principle of the developed system}

The structure block diagram of the developed system is shown in Fig. 3. The system used Atmega250 microcontroller made by ATMEL Corporation as its core. The control system could detect the input rotational speed of the Simulated Front-wheel of the tractor by the mounted proximity sensor with 8 spokes iron wheel on its shaft. The rotational speed data were compared with the reference required seed data $(\mathrm{Kg} / \mathrm{ha})$ and drill row spacing $(\mathrm{cm})$. These data were already stored in the microcontroller memory supplied by the grain drill operator, using the potentiometric switch of the unit. The input values were displayed on the $16 \times 2$ LCD. From these, the appropriate rotational speed of the seed metering shaft was determined. The immediate rotational speed of the seed metering shaft was compared with the desired value to send an appropriate instruction to the variable-rate DC motor control circuit, the variable rate controller in the control circuit was used to control the variable-rate DC motor behavior. The control circuit sent the voltage to variable-rate DC motor regarding the proper calculated rotational speed of the seed metering shaft. The relationship between the sent voltage and rotational speed of the seed metering shaft was obtained and calibrated using laboratory tests for the control system.
Synchronization between forward speed of operation and speed of metering shaft

It is required for the motor to be capable enough to vary its speed according to the forward speed of operation and provide enough torque to rotate the seed metering shaft of the seed drill. To establish synchronization between the forward speed of operation and speed of the metering shaft, The relationship between the sent voltage and rotational speed of DC motor to rotate seed metering shaft was obtained and calibrated using laboratory tests for the control system, shows the linear relation between the input voltage and output RPM of the motor. The maximum rotational speed of the metering shaft was calculated corresponding to the maximum speed of operation and seed rate for seed drill.

\section{Evaluation of seed metering system}

The performance of the metering device can be checked more readily and more reliably in the laboratory than in the field (Kapner et.al., 1956). To evaluate developed system existing 9 tynes old seed drill having a fluted roller for metering of seeds with chain and sprocket drive system was used and the developed electronically controlled seed metering system was installed (Fig. 4). The ground wheel of the seed drill was a disconnect to modify the existing seed drill. Variable-rate geared DC motor was used to convert the controlled electrical power into mechanical power. The special mechanical component was used to assist the desired angular change in seed metering shaft and the mounted variable rate geared dc motor on the seed drill. To mount variable rate geared DCM on seed drill a small platform of flat iron having thickness $2 \mathrm{~mm}$ and size $18 \mathrm{~cm} \times 18 \mathrm{~cm}$ was fabricated at side frame of the seed drill. Different slots were given on the platform to adjust the position of the dc motor. DCM was 
mounted on the platform. The gear reduction ratio of 5.22/1 was provided between the variable rate $\mathrm{dc}$ motor and metering shaft to transfer power between them. The rotational speed of variable-rate DCM was determined by the control box of the unit according to the rotational speed of the speed of a simulated front wheel of the tractor and inputs seed rate and row to row spacing were define by the operator through input button.

\section{Test procedure}

Graded seeds of Soybean were used for this study. The experiment was carried out using the existing seed drill coupled with developed electronically controlled seed metering system. The desired seed rate was taken 40, $60,80,100 \mathrm{~kg} / \mathrm{ha}$ and spacing between furrow opener was $20 \mathrm{~cm}$. Performance evaluation of the developed system was conducted under four operating forward speeds of 2.4, 3, 4, and $5 \mathrm{~km} / \mathrm{hr}$. To resemble the operation of the seed drill at 2.4, 3, 4, and $5 \mathrm{~km} / \mathrm{hr}$ speed, the SFW (Simulated front wheel of the tractor) electrical motor was set to run at 40.25, 60.38, 80.21 and $100.65 \mathrm{rpm}$ correspondingly. Three replications were taken at each forward speed with each set seed rate. Seeds were collected from the different furrow openers and percentage variation between the set seed rate and actual seed rate were determined to evaluate the performance of developed system.

\section{Results and Discussion}

The seed rate was controlled by changing in speed of the metering shaft in proportion to the forward speed of operation by altering the speed of geared dc motor. Fig. 5 shows at constant seed rate as forwarding speed of operation increased or decreased, rpm of dc motor also increased or decreased accordingly. It controls dropping of the seed and maintain uniform seed rate over the field in the real-time condition. Results after validation found to be that there was very good agreement between the performance of all electrical components and the developed metering unit. The continuous output signals were provided from both proximity sensors. There was no significant difference between the observed and expected performance.

The relationship between set seed rate (input) and actual seed rate (output) obtained in laboratory trials with developed system are shown in Fig. 6. These observations are taken at 4 different forward speeds of 2.4,3,4 \& 5 $\mathrm{km} / \mathrm{hr}$, and $20 \mathrm{~cm}$ row to row spacing with a full exposed length of the fluted roller. Results have shown that actual seed rate and set seed rate are very closely related.

The average percentage variation between the actual seed rate and set seed rate was found to be within the range of -3.10 to $3.141 \%$ at a different level of forward speeds and seed rates. The maximum percentage variation was found to be at a forward speed of $2.4 \mathrm{~km} / \mathrm{hr}$ and seed rate of $40 \mathrm{~kg} / \mathrm{ha}$. While minimum percentage variation was found to be at 4 $\mathrm{km} / \mathrm{hr} \& 80 \mathrm{~kg} / \mathrm{ha}$, forward speed \& seed rate respectively.

The average percentage variation in actual seed rate over the set seed rate values in each case of experimental trials is presented in table 1. Analysis of tabulated results (Table 1) and Fig. 7, demonstrated that at low set seed rate of 40 and $60 \mathrm{~kg} / \mathrm{ha}$, when forward speed increases the percentage variation of seed rate reduces from high positive value to low positive value which results in actual seed rate value comes closer to set seed rate. Whereas at higher set seed rate of $80 \mathrm{~kg} / \mathrm{ha}$ when forward speed increases, initially the actual seed rate comes closer to set seed rate and then deviate towards negative when forward speed increases further. However, at set seed rate of $100 \mathrm{~kg} / \mathrm{ha}$ as forward speed increases, 
the percentage variation of seed rate is moving from less negative value to the high negative variation which results in actual seed rate is less than the set seed rate.

Fig.1(a) Schematic of electronically controlled Seed metering system

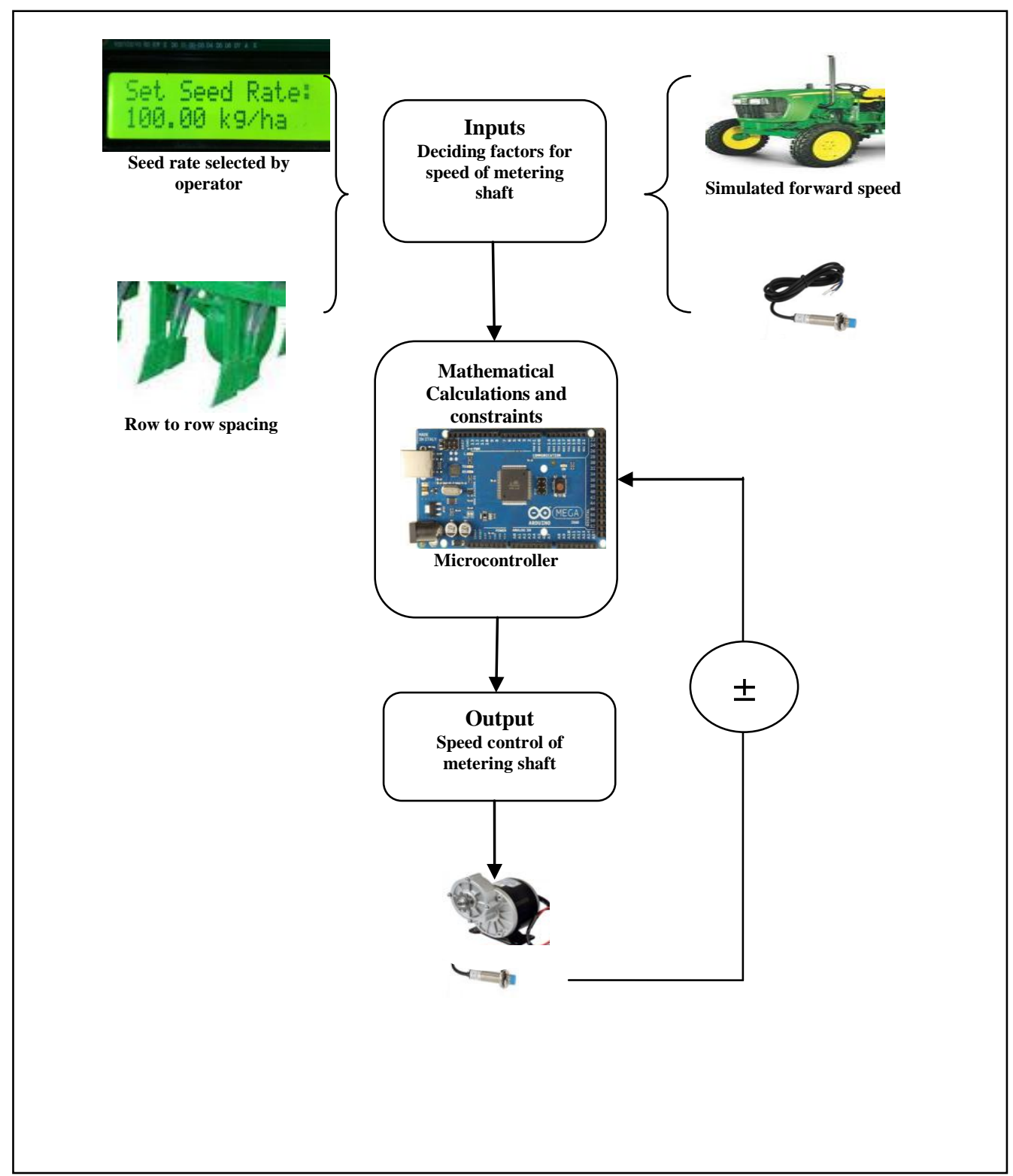


Fig.2 The functional design of the electronically controlled Seed metering system of the seed drill as the control loop system

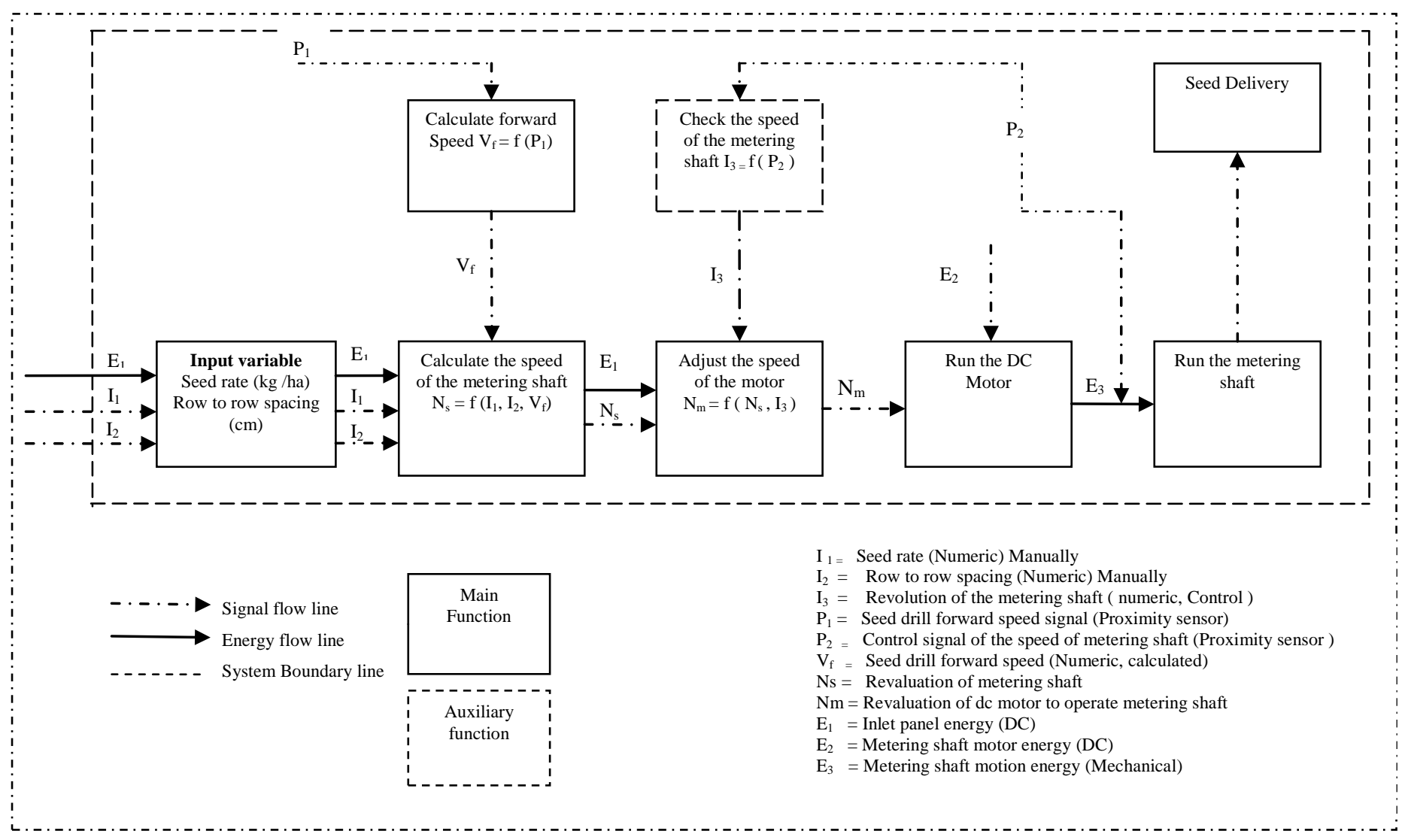

Fig.3 Developed electronically controlled seed metering system

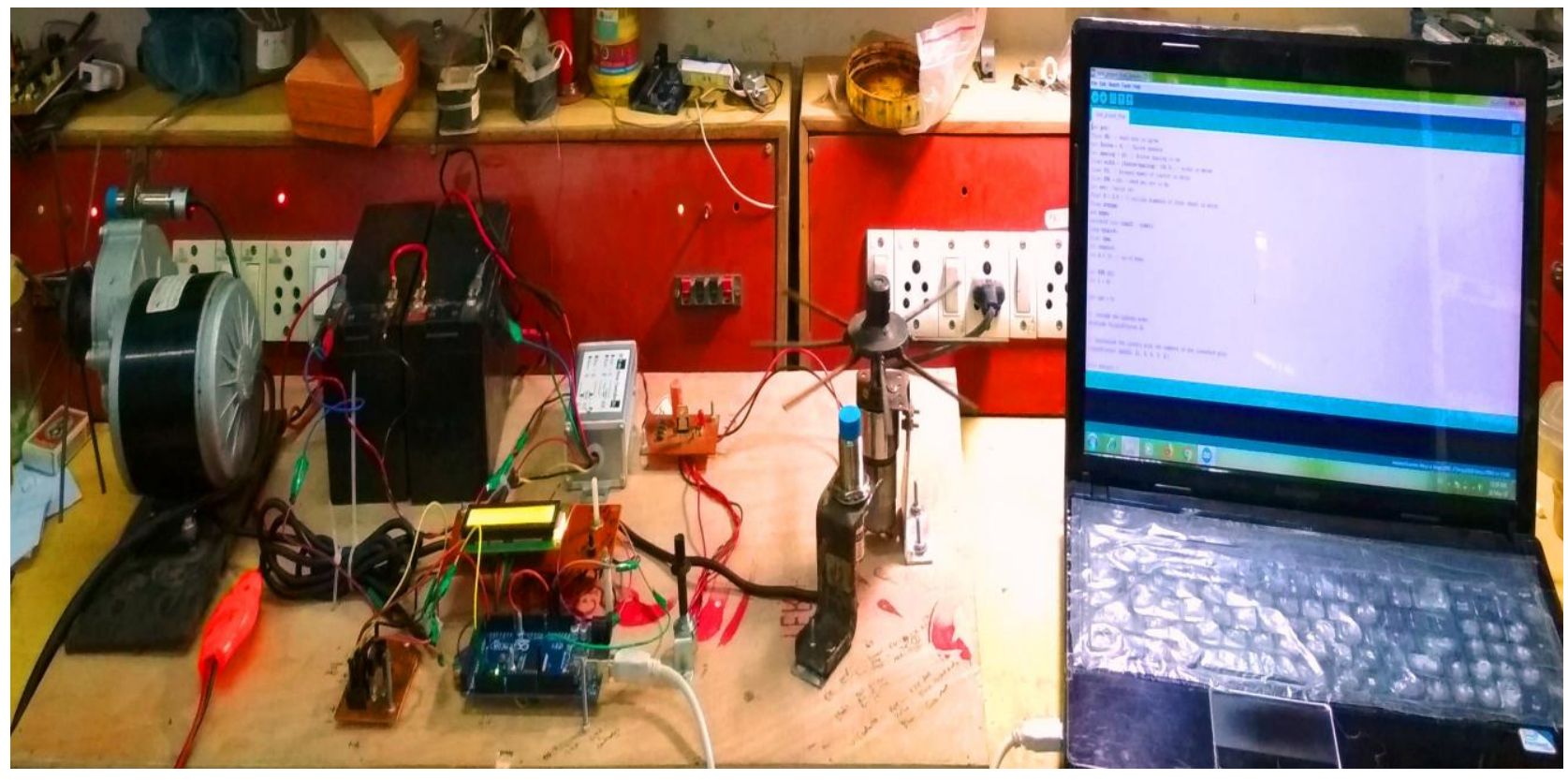


Fig.4 Testing of the developed electronically controlled seed metering system in laboratory

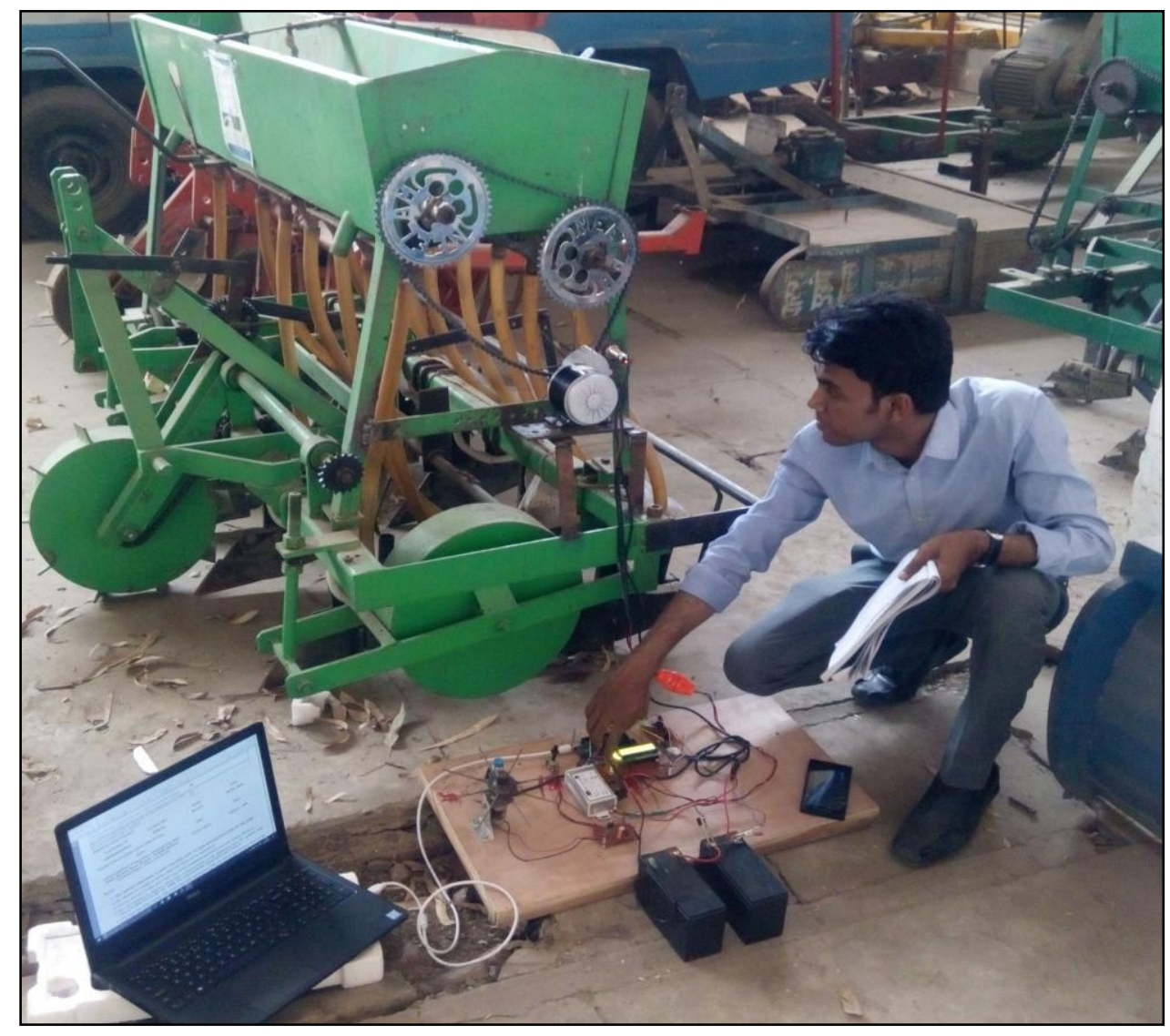

Fig.5 Speed of dc motor to control seed rate at different level of forward speed

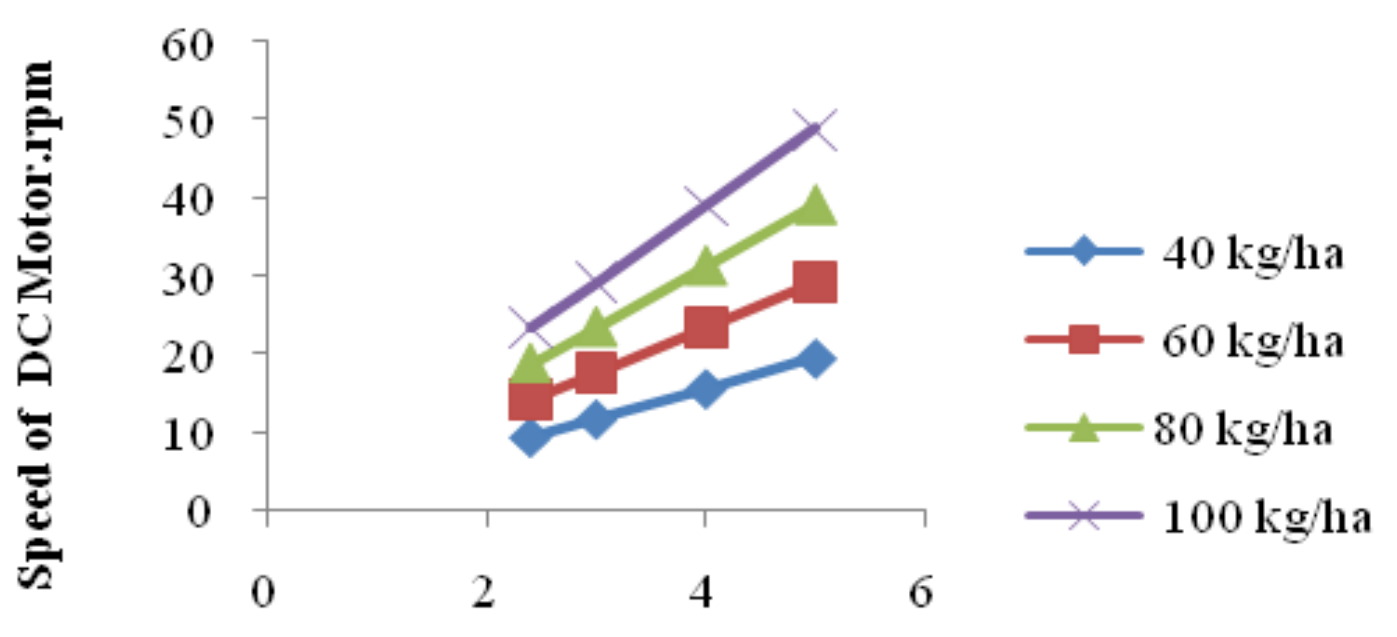

Forward Speed, $k m / h r$ 
Fig.6 Relationship between set seed rate and actual seed rate at different speed level
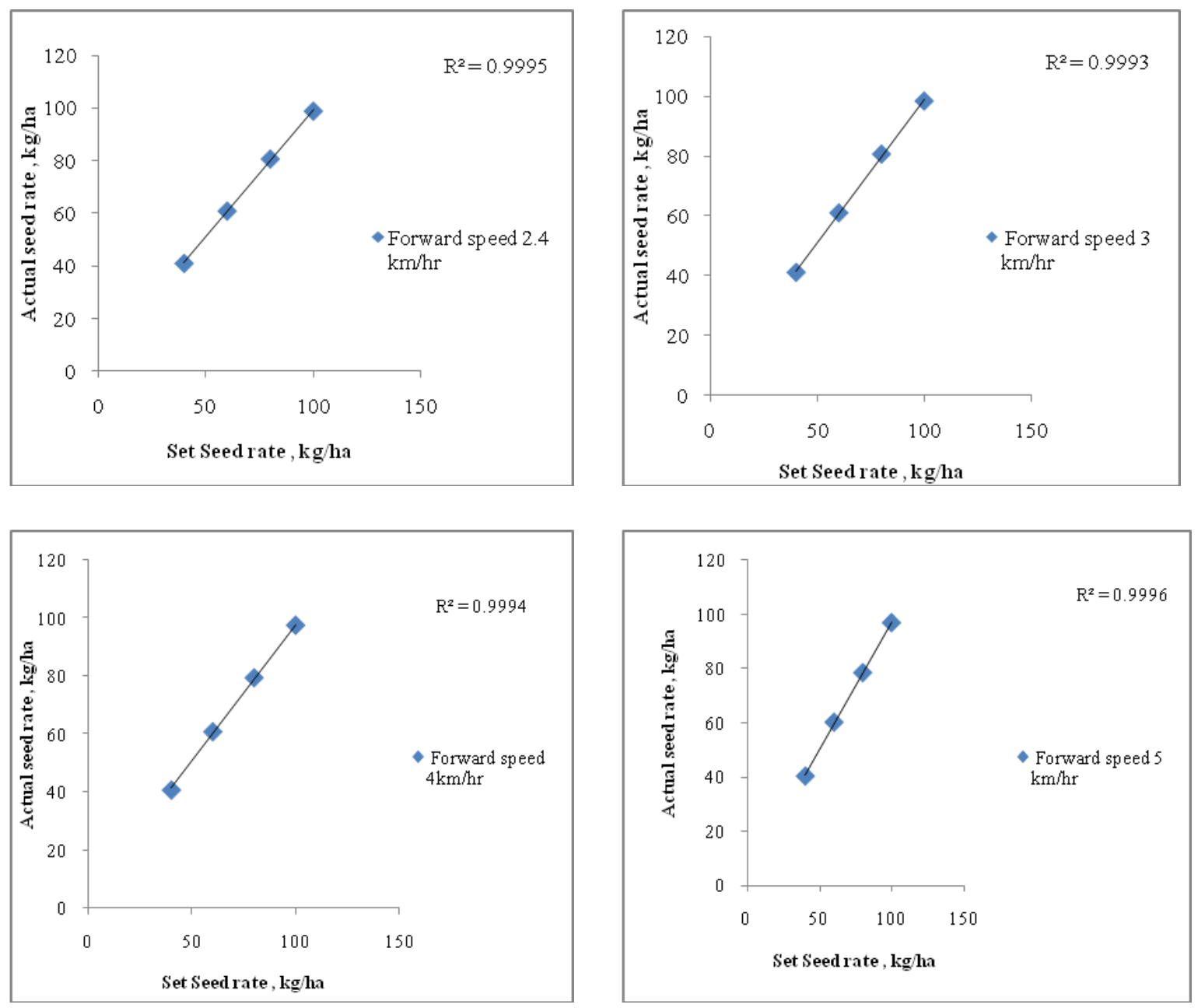

Fig.7 Percentage variation in seed rate at different level of forward speed and seed rate

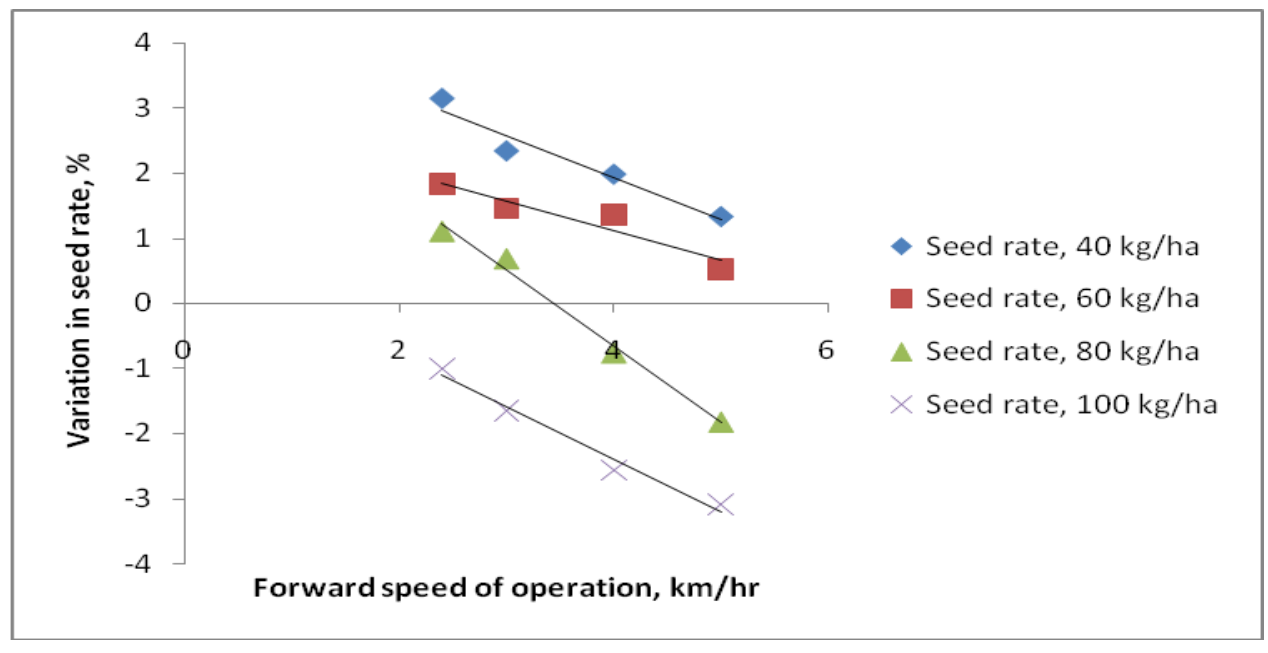


Table.1 Percentage variation in seed rate at different level of forward speed and seed rate

\begin{tabular}{|c|c|c|c|c|}
\hline \multirow{2}{*}{$\begin{array}{c}\text { Forward speed of } \\
\text { operation, } \mathbf{~ k m} / \mathbf{h r}\end{array}$} & \multicolumn{4}{|c|}{ Percentage Variation in seed rate } \\
\cline { 2 - 5 } & $\mathbf{4 0} \mathbf{~ k g} / \mathbf{h a}$ & $\mathbf{6 0} \mathbf{~ k g} / \mathbf{h a}$ & $\mathbf{8 0} \mathbf{~ k g} / \mathbf{h a}$ & $\mathbf{1 0 0} \mathbf{~ k g} / \mathbf{h a}$ \\
\hline $\mathbf{2 . 4}$ & 3.141 & 1.837 & 1.11 & -0.997 \\
\hline $\mathbf{3}$ & 2.333 & 1.462 & 0.689 & -1.648 \\
\hline $\mathbf{4}$ & 1.975 & 1.361 & -0.757 & -2.57 \\
\hline $\mathbf{5}$ & 1.323 & 0.526 & -1.823 & -3.1 \\
\hline
\end{tabular}

In conclusion, the design and development of an electronically controlled seed metering system for seed drill that would enable to get a uniform seed rate over the field was aimed. For proper functioning of the system, the software was created; the hardware design was prepared and installed on the existing seed drill. The developed electronically controlled seed metering mechanism of seed drill tested in a laboratory condition using soybean seed and its metering performance were analyzed. Average seed rate values obtained with the electronically controlled seed metering system were found to be closer to the theoretical seed rate values. A significant success was achieved when using the electronically controlled seed metering system at different levels of speed. When a general evaluation was done concerning usage, developed units enable the suggested optimum seed rate adjustment for seed, a quick and simple adjustment, synchronized and real-time control, and the ability to work under different speed and seed rate inputs. Based on the finding it could be said that synchronization between forwarding speed and metering shaft speed is the most important factor in improving seed rate uniformity in seed drill.

\section{References}

McBratney, A., Whelan, B., Ancev, T. and Bouma, J., 2005. Future directions of precision agriculture. Precision agriculture, 6(1), 7-23.

Kamgar, S., Noei-Khodabadi, F. and Shafaei, S.M., 2015. Design, development and field assessment of a controlled seed metering unit to be used in grain drills for direct seeding of wheat. Information Processing in Agriculture, 2(3-4), pp.169-176.

Karayel, D. 2009. Performance of a modified precision vacuum seeder for no-till sowing of maize and soybean. Soil and Tillage Research, 104(1), pp.121-125.

Iacomi, C. and Popescu, O., 2015. A new concept for seed precision planting. Agriculture and Agricultural Science Procedia, 6, pp.38-43.

Liang, Z., Zhang, D., Yang, L., Cui, T. and Hao, Y., 2015. Experimental Study on Motor Driven Pneumatic Precision Seed-metering Device For Maize. In 2015 ASABE Annual International Meeting (p. 1). American Society of Agricultural and Biological Engineers.

Cay, A., Kocabiyik, H. and May, S., 2018. Development of an electro-mechanic control system for seed-metering unit of single seed corn planters Part I: Design and laboratory simulation. Computers and Electronics in Agriculture, 144, pp.71-79.

Aykas, E., Yalçin, H. and Yazgi, A., 2013. Comparison of sowing performances of single seed sowing machines with axtype burial foot in different regions. Journal of Agricultural Machinery 
Science, 9(1), pp.67-72.

Miller, E.A., Rascon, J., Koller, A., Porter, W.M., Taylor, R.K., Raun, W. and Kochenower, R., 2012. Evaluation of corn seed vacuum metering systems. In 2012 Dallas, Texas, July 29-August 1, 2012 (p. 1). American Society of Agricultural and Biological Engineers.

Singh, R.C., Singh, G. and Saraswat, D.C., 2005. Optimisation of design and operational parameters of a pneumatic seed metering device for planting cottonseeds. Biosystems engineering, 92(4), Pp. 429-438.

St Jack, D., Hesterman, D.C. and Guzzomi, A.L., 2013. Precision metering of Santalum spicatum (Australian Sandalwood) seeds. Biosystems Engineering, 115(2), pp.171-183.

Kamgar, S., Eslami, M.J. and Maharlouie, M.M., 2013. Design, development and evaluation of a mechatronic transmission system to improve the performance of a conventional row crop planter. International Journal of Agronomy and Plant Production, 4(3), pp.480-487.

Bainer, R., Kepner, R.A. and Barger, E.L., 1956. Principles of farm machinery (Vol. 81, No. 2, p. 155).

Minfeng, J., Yongqian, D., Hongfeng, Y., Haitao, L., Yizhuo, J. and Xiuqing, F., 2018. Optimal Structure Design and Performance Tests of Seed metering Device with Fluted Rollers for Precision Wheat Seeding Machine. IFAC-Papers On Line, 51(17), pp.509-514.

Singh, K., Agrawal, K.N., Dubey, A.K. and Chandra, M.P., 2012, November. Development of the controller based seed cum fertilizer drill. In 2012 12th International Conference on Intelligent Systems Design and Applications (ISDA) (pp. 369-374). IEEE.

\section{How to cite this article:}

Rohit Namdeo, Kunj Bihari Tiwari, Atul Kumar Shrivastava, Manish Patel and Bharati Das. 2020. Microcontroller Based Seed Metering System for Precise Soybean Seeding. Int.J.Curr.Microbiol.App.Sci. 9(05): 2778-2788. doi: https://doi.org/10.20546/ijcmas.2020.905.320 